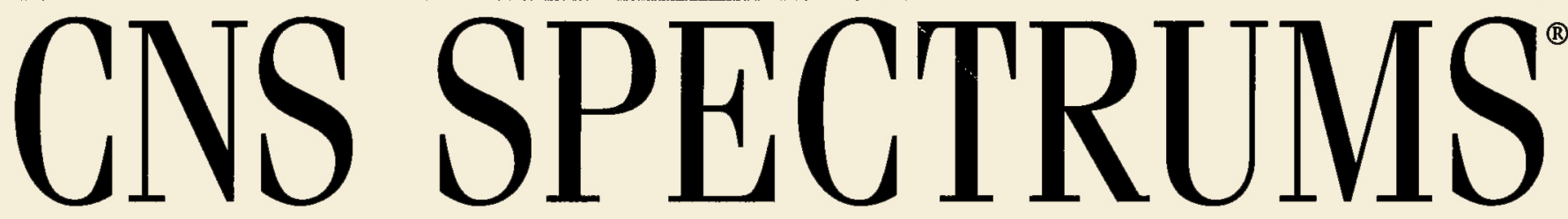

THE INTERNATIONAL JOURNAL OF NEUROPSYCHIATRIC MEDICINE

\title{
ORICINAL RESEARCH
}

Mixed Amphetamine Salts Extended-Release in the Treatment of Adult ADHD: A Randomized, Controlled Trial

R.H. Weisler, J. Biederman, T.J. Spencer, T.E. Wilens, S.V. Faraone,

A.K. Chrisman, S.C. Read, and S.J. Tulloch

\section{REVIEW ARTICLES}

Longitudinal Studies of PTSD:

Dverview of Findings and Methods

T. Peleg and A.Y. Shalev

Memory of the Traumatic Event as a Risk Factor for the Development of

Posttraumatic Stress Disorder:

Lessons from the Study of Traumatic Brain Injury

S. Gil, Y. Caspi, I. Ben-Ari, and E. Klein

Sleep Disturbances in the Aftermath of Trauma and Posttraumatic Stress Disorder

T.A. Mellman and M.M.S. Hipolito

Injury Increases the Risk for PTSD:

An Examination of Potential Neurobiological and Psychological Mediators

D. Koren, D. Hemel, and E. Klein

\section{PEARLS IN CLINICAL NEUROSCIENCE}

The Cognitive-Affective Neuroscience of the Unconscious

D.J. Stein, M. Solms, and J. van Honk 

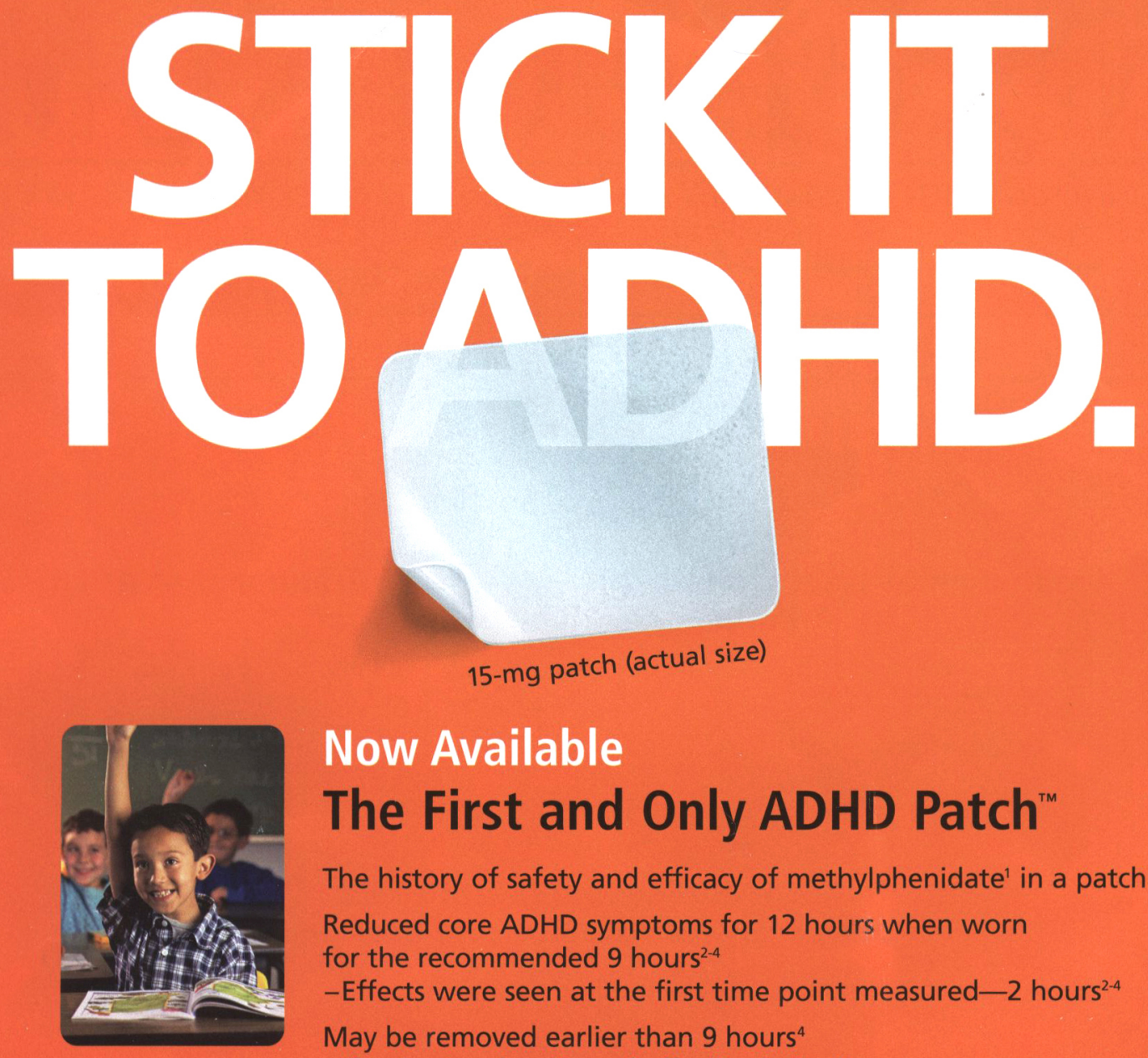

The history of safety and efficacy of methylphenidate' in a patch

Reduced core ADHD symptoms for 12 hours when worn

for the recommended 9 hours ${ }^{2-4}$

-Effects were seen at the first time point measured -2 hours ${ }^{2-4}$

May be removed earlier than 9 hours ${ }^{4}$

-If a shorter duration of effect is desired ${ }^{4}$

-If late-day side effects appear ${ }^{4}$

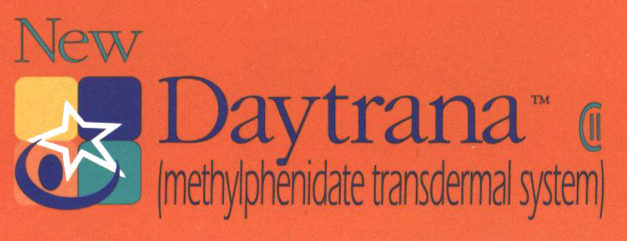

Important Safety Information: CNS Stimulants: Patients with structural cardiac abnormalities or other serious cardiac problems should generally not be treated with stimulants. Physicians should take a careful patient history, including family history, and physical exam, to assess the presence of cardiac disease. Patients who report symptoms of cardiac disease such as exertional chest pain and unexplained syncope should be promptly evaluated. Use with caution in patients whose underlying medical condition might be affected by increases in blood pressure or heart rate.

Daytrana: Patients with allergies to methylphenidate or other ingredients in Daytrana should not receive Daytrana. Skin irritation or contact sensitization may occur. Patients should avoid applying any external heat to the Daytrana patch.

Common adverse events reported by patients who received Daytrana in clinical trials were decreased appetite, insomnia, nausea, vomiting, decreased weight, tics, affect lability, and anorexia, consistent with adverse events commonly associated with the use of methylphenidate.

Methylphenidate: Chronic abuse of methylphenidate can lead to marked tolerance and psychological dependence. Careful supervision following withdrawal from abuse is warranted, as severe depression may occur. Methylphenidate should not be used in patients with marked agitation; glaucoma; tics, diagnosis or a family history of Tourette's syndrome; or current/recent use of monoamine oxidase inhibitors (MAOIs). Frank psychotic episodes, new psychosis, mania, aggression, growth suppression, and visual disturbances have been associated with the use of stimulants and discontinuation of treatment may be appropriate. Use with caution in patients with a history of: psychosis; seizures/EEG abnormalities; bipolar disorder; depression; drug dependence or alcoholism. Hematologic and growth monitoring are advised during prolonged therapy.

\section{Please see Brief Summary of Prescribing Information on adjacent page.}

References: 1. Elio J. Attention deficit/hyperactivity disorder: phormacotherapy. Psychiatry. 2005;2:27-35. 2. Dato on file, Shire US Inc, 2006. 3. McGough JJ, Wigol SB, Abikoff H, et al. A randomized, double-blind, placebo-controlled, laboratory classroom assessment of methylphenidate tronsdermal system in children with AOHD. I Atten Disord. 2006;9:476-485. 4. Daytrana [package insert]. Wayne, Pa: Shire US Inc; 2006. 
BRIEF SUMMARY: Consult the full prescribing information for complete product information. Daytrana'" (methyiphenidate transdermal system)

INDICATION AND USAGE

CII Rx Only

Attention Defleclt Hyperactlvlty Dizorder (ADHD): Daytranat' (methylphenidate transdermal system) is indicated for the efficacy of Daytranatu was established in two controled clinical trials in children with ADHD. Adequate diagnosis requires the use not only of medical but of special psychological, educational, and social resources. Learning

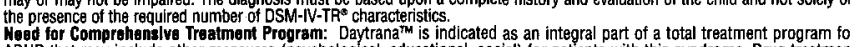
ADHD that may include other measures (psychiological, educational, social) for patients with this syndrome. Drug treatment may not be indicated for all chidren with this syndrome. Stimulants are not intended for use in the child who exhibits insufficient, the decision to prescribe stimulant medication will depend upon the physician's assessment of the chronicity and Severity of the child's symptoms.
Long-Term Use: The feffectiveness of Daytranatw for Iong-term use, l.e., for more than 7 weeks, has not been systematically

evaluated in controlled trials. The physician who elects to use Daytranati for extended periods should p
the long-term usefulness of DaytranaT for the individual patient (see DOSAGE AND ADMHISTRATION).
CONTRAINDICATIOHS

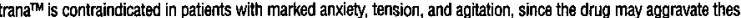

Sypersensittlutty to Methylphenldate: Daytrana ${ }^{\top M}$ is contraindicated in patients known to be hypersensitive to methylphenidate or other components of the product (polyester/ethylene vinyl acetate laminate film backing, acrylic adhesive,
sillcone adhesive and fluoropolymer-coated polyester). Glaucoma: Daytrana $\mathrm{a}^{\mathrm{T}}$ is contraindicated in patients with glaucoma

SEQ ADVERSE REACTHONS). Moneamine 0xidass Inhibitors: DaytranaT' is contraindicated during treatment with monoamine oxidase inhibitors, and also within a minimum of 14 days following discontinuation of treatment with a monoamine oxidase inhibitor (hypertensive crises may result).

Serlous Cardlovascular Events

Sudden death has been reported in association with CNS stimulant treatment at usual doses in children and adolescents with structural cardiac abnormalities or other serious heart problems. Although some serious heart problems alone carry an serious structural cardiac abnormalities, cardiomyopathy, serious heart rhythm abnormalities, or other serious cardiac
problems that may place them at increased vulnerability to the sympathomimetic effects of a stimulant drug. Sdulls Although the role of stimulanis in these adult cases is also unknown, adults have a greater likelithood than children of having serious cardiac problems. Adults with such abnormalities should also generally not be treated with stimulant drugs. Stimulant medications cause a modest increase in average blood pressure (about $2-4 \mathrm{mmHg}$ ) and average heart rate (about 3
$6 \mathrm{bpm}$ ) (see ADVERSE AEACTIONS), and individuals may have larger increases. Whille the mean changes alone would not be
expected to have short-ererm consequences, al patients should be monitored for larger changes in heart rate and blood pressure. Caution is indicated in treatllng pationts whose underlying medical conditions might be compromised by increases in
blood pressure or heart rate, 6.9 ., those with pre-existing hypertension, heart tailure, recent myocardial infarction, or Assessing Cardilovascular Status in Patfents Baing Traated With Simulant Medicallons

Children, adolescents, or adults who are being considered for treatment with stimulant medications should have a careful his-
tory (including assessment for a tamily history of sudden death or ventricular arrhythmia) and physical exam to assess for the presence of cardiac dissase, and should receive further cardiac evaluation if findings suggest such disease (e.g., electro-
cardiogram and echocardiogram). Patients who develop symptoms such as exertional chest pain, unexplained syncope, or

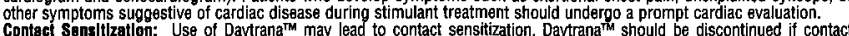
sensitization is suspected. Erythema is commonily seen with use of Daytrana $a^{\text {TM }}$ and is not by itself an indication of ef ensitization. However, sensitzation should be suspected if erythema is accompanied by evidence of a more intense local reaction (edema,
papules, vesicles) that does not significantly improve within 48 hours or spreads beyond the patch site. Diagnosis of allergic contact dermatitis should be corroborated by appropriate diagnostic testing.
Patients sensitized from use of Daytranatw, as evidenced by development of an allergic contact dermatitis, may develop systemic sensitization or of other systemic reactions if methylphenidate-containing products are taken via other routses, $e . g$.

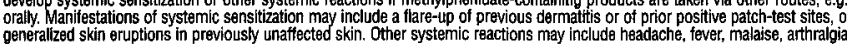
diarthea, or vomitipg.
Patients who develop contact sensitization to Daytrana ${ }^{\text {TMM }}$ and require oral treatment with methylphenidate should be
lnitiated on oral medication under close medical supervision. It is poss blete that some patients sensitized to methylphenidate by exposure to Daytrana ${ }^{T M}$ may not be able to take methylphenidate in any form,
A study designed to provoke skin sensitization revealed a signal for Daytrana ${ }^{T}$ to be an irritant and also a contact sensitizer.

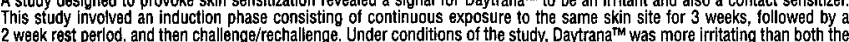

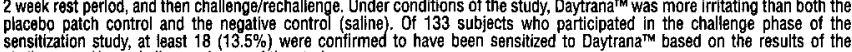
challenge and/or rechallenge phases of the study. Using Daytranare as prescribed, alternating application sites on the hip, no cases of contact sensitization were reported
However since patlents were not specifically assessed tor sensitization in the clinical effectiveness studies, it is unknown what the true incidence of sensittze

Pro-Exlating Prychosis
Administrat on of tsimulants may exacerbate symptoms of behavior disturbance and thought disorder in patients with a preoxisting psychoil

Particular care should be taken in using stimulants to treat ADHD in patients with comorbid bipolar disorder because of concern for possibje induction of a mixed manic episode in such patients. Prior to initiating treatment with a stimulant, patients
with comorbid depressive symptoms should be adequately screaned to determine it they are at risk for bipolas disorder, such Emergonce of Now Psychoilc or Manlc Symptoms cents without a prio history of psychotic illness or mania can be caused by stimulants at usual doses. If such symptems
occur, consideratlon should be glven to a possible causal role of the stimulant, and discontinuation of treatment may be occur, consideratlon should be glven to a possible causal role of the stimulant, and discontinuation of treatment may $\mathrm{b}$
appropriate. In a pooled analysis of multiple short term, placebo-controlled studies, such symptoms occurred in about o.1\%
(4 patients with events out of 3,482 exposed to methylphenidate or amphetamine for several weeks at usual doses) of stim-

uflant-treated patients compared to 0 in placebo-treated patients.
Agpresslon
Agressive behavior or hostility is often observed in children and adolescents with ADHD, and has been reported in clinica

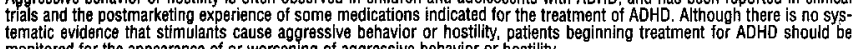
monitored for the appearance of or worsening of aggressive behavior or hostlity

Long-Torm Suppression of Growth: Careful follow-up of weight and height in children ages 7 to 10 years who were randomnewly methylphenidate-treated and non-medication treated children over 36 months (to the ages of 10 to 13 years) suggest that consistently medicated children (i.e., treatment for 7 days per week throughout the year) have a temporary slowing in
growth rate (on average, a total of about 2 cm less growth in height and $27 \mathrm{~kg}$ less growth in weight over 3 years), whthout uvidence of growth rebound durlng this period of development. Published data are inadequate to determine whether chronic
use of amphetamines may cause a similar suppression of growth, however, it is anticipated that they likely have this effect as use of amphetamines may cause a similar suppression of growth, however it is anticipated that they likely have this effect as
well. Therefore, growth should be monitored during treatment with stimulants, and patients who are not growing or gaining height or weight as expected may need to have their treatment interrupteded.
silzures: There is some clinical evidence that stimulants may lower

history of seizures, in patients with prior EEG abnormalities in absence of seizures, and, very rarely, in patients without
history of seizures and no prior $E E G$ evidence of seizures. In the presence of seizures, the drug should be discontinut VIsual ol olsturbance: Difficuifties with accommodation and blurring of vision have been reported with stimulant treatment Use In Children Under six Years of Age: Daytrana
efficacy in this age group have not been established.

Drug Dependence

Dad to marked told be given cautiously to patients with a history of drug dependence or alcoholism. Chronic abusive use can

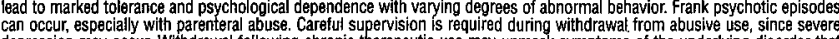
depression may occur. Withdrawal following chronic therapeutic use may unmask symptoms of the underlying disorder tha

Patients Using External Hoat: All patients should be advised to avoid exposing the Daytrana external heat sources, such as heating pads, electric biankets, heated water beds, etc., while wearing the patch.
potential for temperature-dependent increases in methylphenidate release of greater than 2-fold from the patch.

Hematologic Monitoring: Periodic CBC, differential, and platelet counts are advised during prolonged therapy.
imtormatlon for Pallents: Patients should be informed to apply Daytrana $a^{T m}$ to a clean, dry site on the hip, which is not oily, damaged, or irritated. The site of application must be alternated daily. The patch should not be applied to the waistline, or where
tight clothing may rub it. Daytrana $a^{T M}$ should be applied 2 hours before the desired effect. Daytrana $a^{T M}$ should be removed approximately 9 hours after it is applled, although the effects from the patch will last tor several more hours.
The parent or caregiver should be encouraged to use the administration chart included with each carton of Daytrana ${ }^{\text {Th }}$ to monthor application and removal time, and method of disposal.
if there is an unacceptable duration of appetite loss or insomnia in the evening, taking the patch off earlier may be Skin rediness or itching is common with Daytrana ${ }^{3 w}$, and small bumps on the skin may also occur in some patients. If any swellin or bitistering occurs the patch should not be worn and the patient should be seen by the prescriber.
Orug interactions: Daytranars should not be used in patients peing treated (currently or within the preceding two weeks)

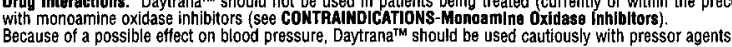

Because of a possible effect on blood pressure, Daytrana ${ }^{\text {TM }}$ should be used cautiously with pressor agents.
s://doi.org/10.1017/S1092852900013584 Published online by Cambridge University Press
Methylphenidate may decrease the effectiveness of drugs used to treat hypertinsion.

Human pharmacologic studies have shown that methylphenidate may inhibit the metabolism of coumarin anticoagulants

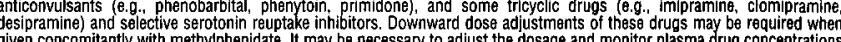
(or, in the case of coumarin, coagulation times), when initiating or discontinuing methylphenidate. (or, in the case of coumarin, coagulation times, when initiating or discontinuing methy phenidate,
Serious adverse events have been reported in conncomitant use of methylphenidate wilth cloniding, although no causallty for the
combination has been established. The safety of using methylphenidate in combination with clonidine or other centrally acting alpha-2-agonists has not been systematically evaluated.
Carelnogenesis, Mutagenesis, and Impairment of Fortllity: Carcinogenicity studies of transdermal methylphenidate have not been performed. In a lifetime carcinogenicity study of oral methylphenidate carried out in B6C3FF mice, methylphenicat
caused an increase in hepatocelluar adenomas and, in males only, an increase in hepatoblastomas, at a daily dose of approximately $60 \mathrm{mg} / \mathrm{kg} / \mathrm{day}$. Hepatoblastoma is a relatively rare rodent malignant tumor type. There was no increase in tota Orally administered methylphenidate did not cause any increases in tumors in a lifetime carcinogenicity study carried out in Prally administered methylphenidate did not cause any increased ay.
F344 rats: the highest dose used was approximately 45 mgkg/day.
in a 24 -week oral carcinogenicity study in the trans

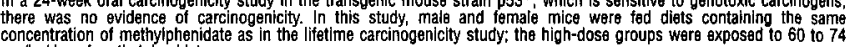
mg/kg/day of methyiphenidait.

Was not mutagenic in the in vitro Ames reverse mutation assay or in the in vitro mouse lymphoma cell forward mutation assay, and was negative in vivo in the mouse bone marrow micronucleus assay. Sister chromatid exchanges Methyiphenidate did not impair fertility in male or temale mice that were fed diets containing the drug in an 18-week Continious Breeding study. The study was conducted at doses up to $160 \mathrm{mg} / \mathrm{kg} / \mathrm{day}$.
Prognancy

Pragnancy
Pregranancy Category C: Animal reproduction studies with transdermal methylphenidate have not been performed. In a study in
which oral methy phenidate was given to pregnant rabbits during the period of organogenesis at doses up to $200 \mathrm{mg} / \mathrm{kg} / \mathrm{day}$ no which ora methylphenidate was given to pregnant rabbits during the period of organogenessis at doses up to $200 \mathrm{mg} / \mathrm{kg}$ day no
teratogenic effects were seen, although an increase in the incidence of a variation, dilation of the lateral ventricles, was se日en at 200

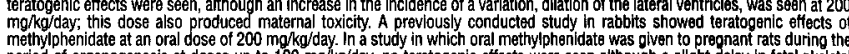

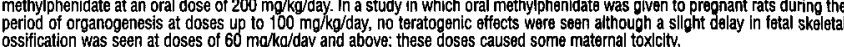
assification was seen at doses of 60 mg/kg/day and above; these doses caused some maternal toxlcilty.
In a study in which oral methylphenidate was given to rats throughout pregnancy and lactation at doses up to $60 \mathrm{mg} / \mathrm{kg} / \mathrm{day}$. Offspring weights and survival were decreased at $40 \mathrm{mg} / \mathrm{kg} /$ day and above; these doses caused some maternal toxicity
Adequate and well-controlled studies in pregnant women have not been conducted. Daytrana ${ }^{\text {th }}$ should be used during preganancy only if the potential benefit justifies the potential risk to the tetus.
Wursing Wothers: It is not known whether methylphenidate is excreted in human milk. Because many drugs are excreted in human milk, caution should be exercisad if Daytranat'm is administered to a nursing woman.

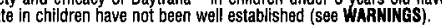
In a study conducted in young rats, methylphenidate was administered orally at doses of up to $100 \mathrm{mog} / \mathrm{kg} / \mathrm{day}$ for 9 weeks,
starting early in the postnatal period (Postnatal Day 7) and continuing through sexual maturlty (Postnatal Weak 10). When these animals were tested as adults (Postnatal Weeks 13-14), dacreased spontaneous locomotor activity was observed in
males and females previously treated with $50 \mathrm{mg} / \mathrm{kg}$ /day or grater, and a deficit in the acquisition of a speciflc learning lask 5 mg/kg/day. The clinical significance of the long-term behavioral effects observed in rats is unknown.

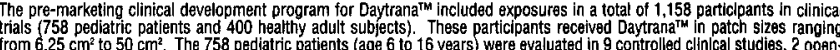
label clinical studies, and 4 clinical pharmacology studies. Adverse reactions were assessed by collecting adverse events data, the results of physical examinations, vital signs, weights, laboratory analyses, and EC

Adverse Findings in Clinical Irials With Daytran

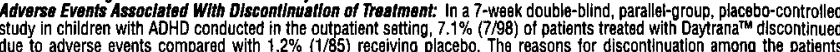
reated with Daytrana $a^{T M}$ were application site enthema, application site reaction, confusional state, crying, tics, headaches, Adverse Events Oceurring at an Incldence of 5\% or More Among Pallents Thestod With Daytrensm: Tabie 1 enumerates study in children with ADHD conducted in the outpatient setting. TABLE 1: Most Commonly Reported Treatment-Emaryent Adverse Events ( $\geq 5 \%$ and $2 \times$ Placebo) in a 7 -waek Placebo-controlled Study Number (\%) of Subject

\begin{tabular}{|c|c|c|}
\hline Adverse Event & $\begin{array}{c}\text { Daytrana'Th } \\
(\mathbb{N}=98)\end{array}$ & $\begin{array}{l}\text { Placebo } \\
(\mathrm{N}=85)\end{array}$ \\
\hline Number of Subjects With $\geq 1$ & $\ln 74 \quad(76)$ & $\begin{array}{l}49 \quad(58) \\
\end{array}$ \\
\hline Nausea & 12 (12) & $2(2)$ \\
\hline Vomiting & $10(10)$ & $4(5)$ \\
\hline Nasophayngitis & $5(5)$ & $2(2)$ \\
\hline Weight decreased & 9 (9) & $0 \quad(0)$ \\
\hline Anorexia & $5(5)$ & $1(1)$ \\
\hline Decreased appetite & $25(26)$ & $4 \quad(5)$ \\
\hline Affect lability ${ }^{*}$ & $6(6)$ & $0 \quad 0)$ \\
\hline Insomnia & $13(13)$ & $\begin{array}{ll}4 \quad(5) \\
\end{array}$ \\
\hline Tic & $7(7)$ & $0(0)$ \\
\hline$\overline{\text { Nasal c }}$ & $6(6)$ & 1 (1) \\
\hline
\end{tabular}

Six subjects had affect lability, all judged as mild and described as increased amo-
tionally sensititive, emotionality, emototonal instability, emotional lablity, and interSkin Irrtitatlon: Daytrana ${ }^{T M}$ is a dermal irritant The malority of sublects in the olvotal phase til
clinical efficacy study had minimal to definite erythema. This erythema generally caused no or
minimal discomfort and dld not usually interfere with therapy or result in discontlinuation from
treatment. If erythema, edema, and/or papules hours after patch removal, further evaluation should be sought. Enthema is not by itself an indication of contact sensitization. However,
sensitization should be consldered if erythema is accompanied by edema, papules, vesicless, of be corroborated by appropriate dlagnostlc testing (se日 WARMings - Contact Sonestization). Daytrana up to 40 -month duratlon In 191 children with
$A D H$, the most frequently reported treatmentEmergent adverse events in pedlatric patients
treated with Daytranatw for 12 hours daly wore anorexia (87 sub|acts, $46 \%$ ), Insomnia (57 sub-
jects, 30\%), viral infoction 54 subjects, $28 \%$ ) and headache (53 subjects, $28 \%$ ). A total of 45 (24\%) subjects were withdrawn from the study because of treatment-emergen
adverse events. The most common events leading to withdrawal were application site reaction (12 subjects, $6 \%$ ), anorexia (7

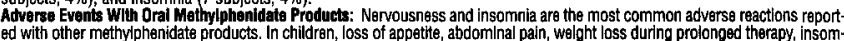
nia, and tachycardla may occur more frequently, however, any of the other adverse reactions listed below may also occur.

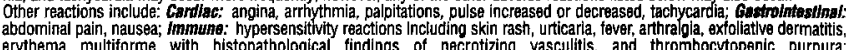

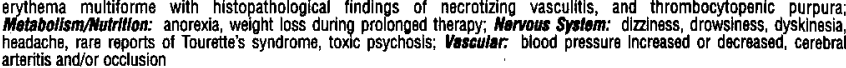
Although a definitite causal relationship has not been astablished, the following have been reported in patients taking
methylphenidate: Blood/fymphatle: leukopenia and/or anemia; Hoptobllary: abnormal liver function, ranging from

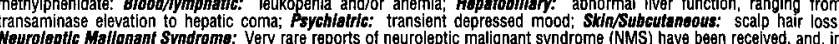
most of these, patients were concurrently receiving therapies associated with NMS. In a single repart, a ten-year-oidd boy who mad been taking methylphenidate for approximately 18 months experienced an NMS-like vevent within 45 minutes of
ingesting his first dose of venlataxine. It is uncertain whether this case represented a drug-drug Interaction, a response to Gither drug alone or some other caus.

Controlled Substance Class: Daytrana ${ }^{\text {TM }}$ (methylphenidate transdermal system), like other methylphenidate products, is classifled as a Schedulle If controlled substance by federal regulation.
Abuse, Dependence, and Tolerance: See WARMiNGS-Drug Dependence for boxed warning containing drug abuse and dependence information.

Signs and Symploms: Signs and symptoms of acute methylphenidate overdosage, resulting principally from overstimulation hyperreflexia, muscle twitching, convulsions (may be followed by coma), euphorla, coniusion, hallucinations, idelirium, dryness of muccus membranes.

Recommended Treatment: Remove all patches immediately and cleanse the area(s) to remove any remaining adhesive. The continuing absorption of methylphenidate from the skin, even after removal of the patch. should be considered when treating injury and against external stimulit that would aggravate overstimulation already present. Intensive care must be provided to maintain adequate circulation and respiratory exchange; external cooling procedures may be required for hyperpyrext.

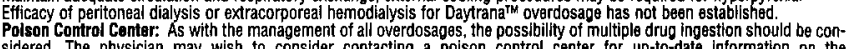
sidered. The physician may wish to consider contacting a poison control center for up-to-date Information on the Do not store patches unpouched. Store at $25^{\circ} \mathrm{C}\left(77^{\circ} \mathrm{F}\right)$; excursions permitted to $15-30^{\circ} \mathrm{C}\left(59-86^{\circ} \mathrm{F}\right)$ [ [se日 USP Controlled
oom Temperature]. Once the tray is opened, use contents within 2 months. Apply the patch immediately upon removal from the protective pouch. Do not store patches unpouched. For transdermal use only.
REFERENCE

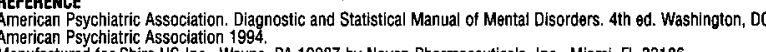

American Psychiatric Association 1994, 19087 by Noven Pharmaceuticals, Inc., Miami, FL 33186.

For more information call $1-800-828-2088$ or visit www shire.com
Dot Matrix $x^{T}$ is a trademark of Noven Pharmaceuticals, Int.

Daytranam Is a trademark of Shire Pharmacestitcals Ireland Limited.
02006 Shire Pharmaceuticals Ireland Limited.

Rx Only

5521027002 Rev. 06/06

DBSA

Shire 


\section{EDITOR}

Jack M. Gorman, MD

Mount Sinai School of Medicine

New York, NY

\section{FOUNDING EDITOR}

Eric Hollander, MD

Mount Sinai School of Medicine

New York, NY

\section{INTERNATIONAL EDITOR}

Joseph Zohar, MD

Chaim Sheba Medical Center

Tel-Hashomer, Israe

\section{ASSOCIATE INTERNATIONAL EDITORS}

\section{EUROPE}

Donatella Marazziti, MD

University of Pisa

Pisa, Italy

\section{MID-ATLANTIC}

Dan J. Stein, MD, PhD

University of Cape Town

Cape Town, South Africa

\section{FAR EAST}

Shigeto Yamawaki, MD, PhD

Hiroshima University School

of Medicine

Hiroshima, Japan

\section{CONTRIBUTING WRITERS}

Sharon Gil, PhD

Ehud Klein, MD

Danny Koren, PhD

Thomas A. Mellman, MD

Arieh Y. Shalev, MD

Richard H. Weisler, MD

\section{COLUMNIST}

Dan J. Stein, MD, PhD

\section{MEDICAL REVIEWER}

David L. Ginsberg, MD

\section{CME COURSE DIRECTOR}

Eric Hollander, MD

\section{SUPPLEMENT EDITORS}

Eric Hollander, MD

Joseph Zohar, MD

\section{NEUROLOGISTS}

Mitchell F. Brin, MD

University of California, Irvine Irvine, CA

Jeffrey L. Cummings, MD

University of California, Los Angeles Los Angeles, CA

Jerome Engel, Jr., MD, PhD

University of California, Los Angeles Los Angeles, CA

Mark S. George, MD

Medical University of South Carolina Charleston, SC

Richard B. Lipton, MD

Albert Einstein College of Medicine Bronx, NY

C. Warren Olanow, MD, FRCPC

Mount Sinai School of Medicine

New York, NY

Steven George Pavlakis, MD

Maimonides Medical Center

Brooklyn, NY

Stephen D. Silberstein, MD, FACP

Thomas Jefferson University

Philadelphia, PA

Michael Trimble, MD, FRCP, FRPsych National Hospital for Neurology

and Neurosurgery

London, United Kingdom

\section{PSYCHIATRISTS}

Margaret Altemus, MD

Cornell University Medical College New York, NY

Dennis S. Charney, MD

Mount Sinai School of Medicine

New York, NY

Dwight L. Evans, MD

University of Pennsylvania

Philadelphia, PA

Siegfried Kasper, MD

University of Vienna

Vienna, Austria

Martin B. Keller, MD

Brown Medical School

Providence, RI

Lorrin M. Koran, MD

Stanford University School of Medicine

Stanford, CA
Yves Lecrubier, MD

Hôpital de la Salpêtrière

Paris, France

Herbert Y. Meltzer, MD

Vanderbilt University Medical Center

Nashville, TN

Stuart A. Montgomery, MD

St. Mary's Hospital Medical School

London, United Kingdom

Charles B. Nemeroff, MD, PhD

Emory University School of Medicine Atlanta, GA

Humberto Nicolini, MD, PhD

National Mexican Institute of Psychiatry

Mexico City, Mexico

Stefano Pallanti, MD, PhD

University of Florence

Florence, Italy

Katharine Phillips, MD

Brown Medical School

Providence, $R$

Harold A. Pincus, MD

Western Psychiatric Institute \& Clinic

RAND-University of Pittsburgh Health Institute,

Pittsburgh, PA

Scott L. Rauch, MD

Massachusetts General Hospita

Charlestown, MA

Alan F. Schatzberg, MD

Stanford University School of Medicine

Stanford, CA

Thomas E. Schlaepfer, MD

University of Bonn

Bonn, Germany

Stephen M. Stahl, MD, PhD

University of California, San Diego

La Jolla, CA

Norman Sussman, MD

New York University Medical Schoo

New York, NY

Karen Dineen Wagner, MD, PhD

The University of Texas Medical Branch Galveston, Texas

Herman G.M. Westenberg, MD

University Hospital Utrecht

Utrecht, The Netherlands

Stuart C. Yudofsky, MD

Baylor College of Medicine

Houston, TX

\section{PUBLICATION STAFF}

CEO \& PUBLISHER

Darren L. Brodeur

\section{ASSOCIATE PUBLISHER \\ Elizabeth Katz}

VP, MANAGING EDITOR

Christopher Naccari

\section{VP, SENIOR EDITOR}

Deborah Hughes

SENIOR GLOBAL

ACCOUNT DIRECTOR

Richard Ehrlich

PUBLISHING SALES ASSOCIATE

Kimberly Schneider

MEDIA SALES REPRESENTATIVE

Jodi Malcom
SENIOR EDITOR-CNS SPECTRUMS

José Ralat

\section{ACQUISITIONS EDITORS}

Lisa Arrington

Virginia Jackson

ASSOCIATE EDITOR-

ENDURING MATERIALS

Shelley Wong

\section{ASSOCIATE EDITORS}

Peter Cook

Dena Croog

\section{INTERNS}

Rebecca Nison

Carlos Perkins, Jr

Stephanie Spano

Rebecca Sussman
ART DIRECTOR

Derek Oscarson

GRAPHIC DESIGNER

Michael J. Vodilko

CHIEF FINANCIAL OFFICER

John Spano

OFFICE MANAGER

Manuel Pavón

INFORMATION TECHNOLOGY

Clint Bagwell Consulting

CORPORATION COUNSEL

Lawrence Ross, Esq

Bressler, Amery, and Ross

\section{Publishers of PRIMARY PSYCHIATRY}




\section{FACELIFT COMPLETE!}

\section{Welcome to CNS Spectrums' New Web Portal... www.cnsspectrums.com}

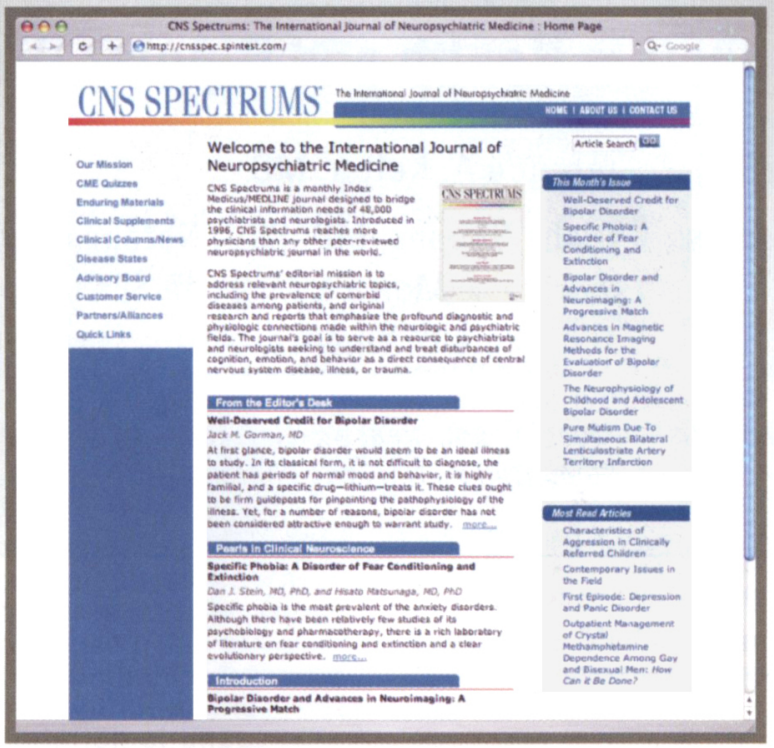

After a six-month top-to-bottom redesign, CNS Spectrums' new web portal is now better than ever - a one-stop source providing the following integrated services based on input from you... our readers:

- Must Read Articles automatically tabulated

- Quick Links to Clinical Review Articles, Columns, News, \& Educational Reviews

- Key Word or Disease State-based Article Search

- Integrated Customer Service Tools
- elearning via Enduring Materials \& Monthly CME Section

- And a host of additional services and features... including simple hyper-link access to MBL's other CNS sources: www.primarypsychiatry.com and www.psychiatryweekly.com

To learn more, please visit: www.cnsspectrums.com or www.mblcommunications.com

\section{PRIMARY PSYCHATRY CNS SPECTRUMS PsychiatryWeekly:}

A Global Commitment to Advancing CNS Science, Clinical Practice, and Evidence-Based Medicine 


\section{EDITOR'S LETTER}

573 Trauma, Its Criteria, and Its Aftermath

Jack M. Gorman, MD, Mount Sinai School of Medicine

\section{INTRODUCTION}

\section{Confronting Trauma's}

\section{Early Aftermath and the Risk for Posttraumatic Stress Disorder}

Ehud Klein, MD, Rambam Medical Center

\section{ORIGINAL RESEARCH}

\section{Mixed Amphetamine Salts}

Extended-Release in the

Treatment of Adult ADHD: A Randomized, Controlled Trial

Richard H. Weisler, MD, University of North Carolina at Chapel Hill; Joseph Biederman, MD, Massachusetts General Hospital; Thomas J. Spencer, MD, Harvard Medical School; Timothy E. Wilens, MD, Harvard Medical School; Stephen V. Faraone, PhD, State University of New York Upstate Medical University; Allan K. Chrisman, MD, Duke University Medical Center; Stephanie C. Read, MS, Shire Pharmaceuticals, Inc.; and Simon J. Tulloch, MD, Shire Pharmaceuticals, Inc.

\section{REVIEW ARTICLES}

\section{Longitudinal Studies of PTSD: Overview of Findings and Methods}

Tamar Peleg, MA, Hadassah University Hospital; and Arieh Y. Shalev, MD, Hadassah University Hospital

603 Memory of the Traumatic Event as a Risk Factor for the Development of PTSD: Lessons from the Study of Traumatic Brain Injury

Sharon Gil, PhD, University of Haifa; Yael Caspi, ScD, MA, Rambam Medical Center; Irit Ben-Ari, PhD, Rambam Medical Center; and Ehud Klein, MD, Rambam Medical Center

611 Sleep Disturbances in the Aftermath of Trauma and Posttraumatic Stress Disorder

Thomas A. Mellman, MD, Howard University; and Maria Mananita S. Hipolito, MD, Howard University

616 Injury Increases the Risk for PTSD: An Examination of Potential Neurobiological and Psychological Mediators

Danny Koren, PhD, University of Haifa; Deborah Hemel, BA, University of Haifa; and Ehud Klein, MD, Rambam Medical Center 



\section{GEFEXORXR:}

BRIEF SUMMARY. See package insert for full prescribing information.

Sulcidality in Children and Adolescents

Antidepressants increased the risk of sulcldal thinking and behavior (suicidality) in short-term studies In children and adolescents wh Major Depressive Disorder (MDD) and other psychlatric disorders
Anyone considering the use of EFFEXOR XR or any other antidepressant in a child or adolescent must Anyone considering the use of EFFEXO XR or any other antidepressant in a child or adolescent must
balance thls riak with the clinical neod. Pattents who are started on therapy should be observed closely Ior clinlcal worsening, sulcldallty, or unusual changes in behavior. Families and caregivers should bo advlsed of the need for close observation and communication with the prescriber. EFFEXO

Pooled anelyses of short-term (4 to 16 weeks) placebo-controlled trlals of 9 antidepressant drugs
(SSRls and others) In children and adolescents with Major Depressive Disorder (MDD), obsessivecompulsive disorder (OCD), or other psychlatric dlsorders (a total of 24 trials involving over 4,400 patients) have revoaled a greater risk of adverse events representing sulcidal thinking or behavior
(sulcldality) during the first fow months of treatment in those receiving antidepressants. The average isk of such events in patients recelving antidepressants was $4 \%$, twice the placebo risk of $2 \%$. No suicides occurrod in these trials.

CONTRAINDICATIONS: Hypersensittvity to venlafaxine hydrochloride or to any excipients in the formulation. Concomitant use in patients taking monoamine oxidase inhibitors (MAOIS). WARNIINGS: Clinical Worsening
and Sulclde Risk- Patients with major depressive disorder (MDD), both adult and pediatric, may experience and Sulclde Risk- Patients with major depressive disorder (MDD), both adult and pediatric, may experience changes in behavior, whether or not they are taking antidepressant medications, and this risk may persist un signiitcant remission occurs. There has been a long-standing concern that antidepressants may have a role in increased the risk of sulcidal thinking and behavicor (suicidality) in short-term studies in children and
ind adolescents with MDD and other psychiatric disorders. It is unknown whether the suicidality risk in pediatr risk extends to adults. All pedlatric patients being treated with antidepressants for any indication should be observed closely for clinical worsening, sulcidality, and unusual changes in behavior, especially or docreases. Adults with MDD or comortid depression in the setting of other psychiatric illness being troated with antidepressants should be observed simllarty for clinical worsening and suicidality, especlally during the intital few months of a course of drug therapy, or at times of dose changes, either increases or decreases. Anxiety, agitation, panic attacks, insomnia, imitability, hostility, aggressivenes impulsivity, akathisia (psychomotor restlessness), hypomania, and mania have been reported in adult an pediatrlc patients being treated with antidepressants for MDD and other indications, both psychiatric an depression and Ar oug a caunce of suicidal impulses symptoms may represent precursors to emerging suicidality. Consideration should be given to changing the therapeutic regimen, including possibly discontinuing the medication, in patients whose depression persistently worse, or who are experiencing emergent suicidality or symptoms that might be precursors of the patient's presenting symptoms. If the decision has been made to discontinue treatment, medication should be tapered, as rapidily as is feasible, but with recognition that abrupt discontinuation can be associated with certain symptoms (see PRECAUTIONS and DOSAGE AND ADMINISTRATION). Families and careglvers and nonpsychlatric, should be alorted abour the noed to monitor patients for the emergence agltation, intitabillty, unusual changes in behavior, and the other symptoms described above, as well as the emergance of sulcldallty, and to report such symptoms immediately to health care providers. Such monitoring should Include daily observation by families and careglvers. Prescriptions for Effexor XR
should be written for the smallest quantity of capsules consistent with good patient management, in order to should be wrltten for the smallest quantly of capsules consistent with good patient management, in order to
reduce the risk of overdose. Families and caregivers of adults being treated for depression should be similarly advised. Screening Patients for Bipolar Disorder: A major depressive episode may be the initial presentatio of bipolar disorder. It is generally believed that treating such an episode with an antidepressant alone may increase the likelihood of precipltation of a mixed/manic episode in patients at risk for bipolar disorder
Whether any of the symptoms described above represent such a conversion is unknown. Prior to initiating antidepressant treatment, patients with depressive symptoms should be screened to determine if they are risk for bipolar disorder; such screening should include a detailed psychiatic history, including a family history Potential for interaction with MAOIs-Adverse reactions, some serious, have been reported in patients who recently dlscontinued an MAOI and starled on venlafaxine, or who recently discontinued venlafaxine prior to inltiation of an MAOI. These reactions included tremor, myoclonus, dilaphoresis nausea, vomiting, llushing, dizziness, hyperthermia with features resembling neuroleptic malignan
syndrome, selzures, and death. Effexor $X$ should not be used in combination with an MAOI, or within syndrome, selzures, and death. Effexor XR should not be used In combination with an MAOI, or with stopping venlafaxlng before starting an MAOI. Serotonin Syndrome-The development of potentially iffe-threatening serotonin syndrome may occur with Effexor XR treatmert, particularly with (i) concomitart use serotonergic drugs and (il) with drugs that impair metaboilsm of serotonin (see CONTRANDICAnONS - MAOIs clinically warranted, careful observation of the pattent is advised, particularly during treatment initiation and dose increases. The concomitant use of Effexor $X R$ with serotonin precursors (such as tryptophan supplements) is no recommended. Sustathed Hypertension-Venlafaxine is associated with sustained increases in blood pressure (BP in some patients. Postmarketing cases of elevated BP requiring immediate treatment have been reported. Pre-existin hypertension should be controlled. Regular monitoring of BP is recommended. For patients experiencing sustaine increase in BP, consider either dose recuction $\alpha$ discontinuation. Mydrlasts. Mydriasis has been reported; monitor
patients with raised intaocular pressure or at risk of acute narrow-angle glaucoma (angle-closure glaucoma) PAECAUTIONS: Genera-D Dtscontinuation of Theatment with Effexor XR. Abrupt discontinuation or dose reduction of venlafaxine at various doses is associated with new symptoms, the frequency of which increased with increased Impaired, diamea, dizziness, dry mouth, dysphoric mood, emotional lability, fasciculation, fatigue, heacaches hypomania, insomnla, irritability, lethargy, nausea, nervousness, nightmares, seizures, sensory disturbances (e.g. paresthesias such as electric shock sensations), somnolence, sweating, tinnitus, tremor, vertigo, and vomiting recommended. If intolerable symptoms occur following a decrease in the dose or upon discontinuation of treatment consider resuming the prevlously prescribed dose. Subsequenty, continue decreasing the dose at a more gradual rate Insomia and hervousness. Treatment-emergent insomnia and nervousness have been reported. In Fhase 3 tials
insomnia led to drug disconthuation in $1 \%$ of both depressed patients and Panic Disorder (PD) patients and in $3 \%$ of both Generalized Anxiety Disorder (GAD) and Social Anxiety Disorder (SAD) patients. Nervousness led to drug discontinuation in $0.9 \%$ of depressed patients, in $2 \%$ of GAD patients, and in $0 \%$ of SAD and PD patients. Changes
in Wofght. Adest Pathents. In short-term MDD trials, $7 \%$ of Effexor XR patients had $\geq 5 \%$ loss of body weight and $0.1 \%$ discontinued for weight loss. In 6 -month GAD studies, $3 \%$ of Effexor XR patients had $\geq 7 \%$ loss of body weigh and $0.3 \%$ discontinued for weight loss in 8-week studies. In 12-week SAD trials, 3\% of Effexor XR patients had $\geq 7 \%$ loss of body weight and no patients discontinued for weight loss. In 12 -week PD trials, $3 \%$ of Effexor XR patients had $27 \%$ loss of body weight, and no patients discontinued for weight loss. The safety and efficacy of venlafaxine in
combination with weight loss agents, inciuding phentermine, have not been established. Coadministration of Effexor $X$. combination with weight loss agents, including phentermine, have not been established. Coadministration of Effexor XF

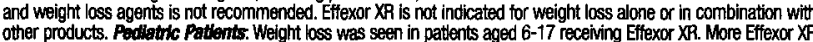
other products. Podlatisc Pationts. Weight loss was seen in pattents aged 6-17 receiving Effexor XP. More Effexor XR patients vs. $3.6 \%$ of placebo patients; $P<0.001$ ) and the SAD study ( $47 \%$ of Effexor XR patients vs. $74 \%$ of placebo patients; $P<0.001$ ). Welght loss was not limited to patients whth treatment-emergent anorexia (decreased appetite) age- and sex-matched peers. The difference between observed and expected weight gain was larger for children <

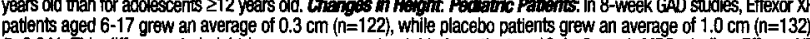
$R=0.041$. This difference in height increase was most notable in patients $<12$. In 8 -week MDD studies, Elexor
patients grew an average of $0.8 \mathrm{~cm}(n=146)$, whlle placebo patients grew an average of $0.7 \mathrm{~cm}$ ( $n=147)$. During the 16-woek, placebo-controlled SAD study, both the Effexor XR $(n=109)$ and the placebo $(n=112)$ patients grew an based on data from age- and sex-matched peers. The difference between observed and expected growth rates was larger for children $<12$ years old than for adolescents $\geq 12$ years old. Changes in Appetthe Adutt Patients
Treatment-emergent anorexia was more commonly reported for Effexor XR (8\%) than placebo (4\%) patients in MDD studies. The discontinuation rate for anorexia was $4.0 \%$ in MDD studies. Treatmentemergent anorexia was more commonly reported for Effexor XR (8\%) than placebo (2\%) patients in GAD studles. The discontinuation rate for anorexia was $0.9 \%$ for up to 8 weeks in GAD studes. Treatment-emergent anorexia was more commonly reported for Effexor XR (20\%) than placebo (2\%) patients in SAD studies. The discontinuation rate for anorexia was $0.4 \%$ for up to placebo (3\%) patients in PO studies. The discontinuation rate for anorexia was $0.4 \%$ for Effexor XR patients in 12-week PD studies. Podfatric Pationts. Decreased appetite was seen in pedlatric patients recelving Effexor XR. In GAD and MDD triels, $10 \%$ of Effexor XR patients aged 6-17 for up to 8 woeks and $3 \%$ of placebo pattents had treatment-emergent anorexia. None of the patients receiving Effexor XR discontinued for anorexla or weight loss. In and placebo, respectively, reported treatment-emergent anorexia (dacreased appettite). The discontinuation rates for anorexia were $0.7 \%$ and $0.0 \%$ for patients receiving Effexor XR and placebo, respectively, the disconthutition rates for
weight loss were $0.7 \%$ for patients receiving either Effexor XR or placebo. Acthation of Manla/thpomanla: Mania weight loss were $0.7 \%$ for patients receiving either Effexor XR or placebo. Acthation of Manka/typomanla: Mania
or hypomania has occurred during short-term depression and PD studles. As with all drugs effective in the treatment IMDD, Effexor XR should be used cautiously in patients with a history of mania. Hypongtremla: Hyponatremia and/or the syndrome of inappropriate antidiuretic hormone secretion (SIADH) may occur with veniafaxine. Consider this in patients who are volume-depleted, elderty, or taking diuretics. Sokzures. In all premarketing depression trials with Discontinue in any patient who develops seizures. Abromal Bibading. Abnormal bleeding imost commonty cchymosis) has been reported. Sentm Cholesterol Elevation: Clinically ralevant increases in serum cholesterol were

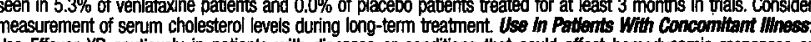
Use Effexor XR cautiously in patients with diseases or conditions that could affect hemodynamic responses of Use Effexor XR cautiously in patients with diseases or conditions that could affect hemodynamic responses or
metabolism. Venlafaxine has not been evaluated in patients with recent history of MI or unstable heart dlsease. metreases in $Q T$ interval (QTC) have been reported in clinical studies. Exercise caution in patients whose underlying medical conditions might be compromised by increases in heart rate. In patients wth renal impaiment or cirmtosis the liver, the clearances of venlafaxine and its active metabolites were decreased, prolonging the ellmination hat-lives.
A lower dose may be necessary; use with caution in such patients. Information for Pattents - frescribers or other health professionals should inform patients, their familles, and their caregivers about the benefits and risks associated health professionals should inform patients, their familles, and their caregivers about the benefits and risks associated Antidepressants in Children and Teenagers is avallable for Effexor XR. The prescriber or health professional should instruct patients, their families, and their caregivers to read the Medication Guide and should assist them in and to obtain answers to any questions they may have. The complete text of the Medication Guide is availabte a unveeffexorxx.com or in the approved prescribing information. Patients should be advised of the following issues and their families, and their caregivers should be encouraged to be alert to the emergence of symptoms listed in WARNINGS: Clinical Worsening and Suickde Risk, especially those seen early during antidepressant treatment and when the dose is adjusted up or down. Families and caregivers of patients shoutt be advised to observe for the emergence of such symptoms on a day-to-day basis, since changes may be abrupt. Such symptoms should be reported to the patient's prescriber or health professional, especially if they are severe, abrupt in onset, or were not suicidal thinking and behavior and indicate a need for very close monitoring and possibly changes in the medication. Caution patients 1) about operating hazardous machinery, including automobiles, until they are reasonably sure that venlafaxine does not adversely affect their abilities; 2) to avoid alcohol while taking Effexor $X R$; and 3) about the risk of serotonin syndrome with the concomitant use of Effexor XR and triptans, tramadol, tryptophan supplements, or other serotonergic agents. Patients should be advised to notify their physician 1 ) if they become pregnant or intend to become pregnant during therapy, or if they are nursing; 2) about other prescription or over-the-counter drugs, including hertal preparations and nutritional supplements they are taking or plan to take; 3 ) if they develop a rash, hives, or related
allergic phenomena; or 4) if they have a history of glaucoma or increased intraocular pressure. Laboratory TestsNo specific laboratory tests are recommended. Dnug interactions - Alcohot: A single dose of ethanol had no effect on the phamacokinetics (PK) of venlafaxine or 0-desmethytwenlataxine (ODV), and venlafaxine did not exaggerate the psychomotor and psychometic effects induced by ettanol. Cimotidhe: Use caution when administering ventafaxine
with cimetidine to patients with pre-existing hypertension or hepatic dysfunction, and the elderly. Diazepaam: A single with cimetidine to patients with pre-existing hypertension or hepatic dysfunction, and the elderly. Diazepam: A single
dose of diazepam did not appear to affect the PK of either venlafaxine or ODV. Venlafaxire did not have any effect on dose of diazepam did not appear to affect the PK of either venlafaxine or ODV. Venlafaxine did not have any effect on induced by diazepam. Halpperidot: Venlataxine decreased total oral-dose clearance of haloperidol, resulting in a $70 \%$ increase in haloperidol AUC. The haloperidol $\mathrm{C}_{\text {max }}$ increased $88 \%$, but the halcperidol elimination half-life was
uncthanged. Lithum: A single dose of lithium did not appear to affect the PK of either venlafaxine or ODV. Venlafaxine unchanged. Lthwum: A single dose of lithium did not appear to affect the PK of either venlafaxine or ODV. Venlafaxine
had no effect on the PK of lithium. Drugs flighty Bound to Plasma Protolns. Venlafaxine is not highly bound to plasma hroteins; coadministration of Effexor XR with a highly protein-bound dnug should not cause increased free concentrations of the other drug. Drigs That inhishit Cytochrome P450 isoonzymos: CYP2D6 Inhibitors: Venlafaxin is metabolized to its active metaboite, ODV, by CYP2D6. Drugs inhibiting this isoenzyme have the potental to increase venlafaxine is coadministered with a CYP2D6 innibitor. Concomitant use of venlafaxine with drug treatmentit(s) that potentially inhibits both CYP2D6 and CYP3A4, the primary metabolizing enzymes for venlafaxine, has not been studied. Use caution if therapy includes venlafaxine and any agent(s) that produces simultaneous inhibition of these two Use caution if therapy indides venlataxine and any agentis) that produces simultaneous inhibition of these two did not affect the $P K$ of imipramine and 2-OH-imipramine. However, desipramine $A U C, C_{\max }$ and $C_{\min }$ increased by $\sim 35 \%$ in the presence of venlafaxine. The 2-OH-desipramine AUCS increased by 2.5-4.5 fold. Imipramine did not affect the PK in the presence of venlafaxine. The 2-OH-desipramine AUCs increased by 2.5-4.5 fold. Imipramine did not affect the PK
of venlafaxine and ODV. Risporidons. Venlataxine slightty inhibited the CYP2D6-mediated metabolism of risperidone to its active metabolite, 9-hyctoxyrisperidone, resulting in a $\sim 32 \%$ increase in risperidone AUC. Venlafaxine coadministration did not significantly alter the PK profile of the total actve moiety (risperidone plus 9-hydroxyrisperidone), CrP3A4: administration resulted in a $28 \%$ decrease in the AUC of a single dose of indinavir and a $36 \%$ cecrease in indinavir $\mathrm{C}_{\text {max. }}$ Indinavir did not affect the PK of venlataxine and ODV. CYP1A2: Ventafaxine did not inhibit CYP1A2 in vitro and in vivo. the PK of a single 550-mg dose of tolbutamide or the CYP2C9-mediated formation of 4-hydroxy-tolbutamide. CYP2C19: Venlafaxine did not inthibit the metabolism of diazepam, which is partlally metabolized by CYP2C19 (see Diazepam

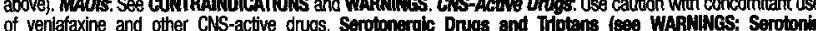
Syndrome): Based on the mechanism of action of Effexor XR and the potential for serotonin syndrome, caution is advised when Effexor XR is coadministered with other dnigs that may affect the serotonergic neurotransmitter systems, such as triptans, SSRIs, other SNRls, linezolid, lithium, tramadal, or St. John's wort. If concomitant treatment of Effexor $X R$ with these dnugs is clinically warranted, careful observation of the patient is advised, particularly during treatment initiation and dose increases. The concomitent use of Effexor XR with typtophan supplements is not
recommended. Eloctrocomndste Therapy (EECD: There are no clinical data establishing the benefit of ECT combined with Effexor XR treatment Carcinogenesis, Murtagenests, Impaiment of Fertility - Carcinogenosis: There was no increase in tumors in mice and rats given up to 1.7 times the maximum recommended human dose (MRHD) on a mg/m² basis. Mutageness: Venlataxine an OOV Were not mutagenic in the Ames reverse mutation assay in in several assays. ODV ellicited a clastogenic response in the in vivo chromosomal aberration assay in rat bone marrow. Impaimment of Fortility. No effects on reproduction of fertility in rats were noted at oral doses of up to 2 times the MRHD on a $\mathrm{mg} / \mathrm{m}^{2}$ basis. Prognancy-Teratogenle Effocts-Prognancy Getogory C. Reproduction studies in rats given 2.5 times, and rabbits given 4 times the MPHD (m $/ \mathrm{m}^{2}$ basis) revealed no malformations in
offspring. However, in rats given 2.5 times the MFHD, there was a decrease in pup weight, an increase in stillborm offspring. However, in rats given 2.5 times the MPHD, there was a decrease in pup weight, an increase in stillborn
pups, and an increase in pup deatths during the first 5 days of lactation when dosing began during pregnancy and pups, and an increase in pup deatts during the first 5 days of lactation when dosing began during pregnancy and
continued until weaning. There are no adequate and well-controlled studies in pregnant women; use Effexor XR during pregnancy only if clearly needed. Monteratogenic Effects. Neonates exposed to Effexor XR late in the third trimester Complications can arise immediately upon delivery. Reports inciude respiratory distress, cyanosis, apnea, seizures, temperature instability, feeding difficulty, vomiting, hypoglycemia, hypotonia, hypertonia, hyperreflexia, tremor,
jitteriness, irritability, and constant crying. This is consistent with a direct toxic efiect of SNRIs or a dug discontinuation jitteriness, irritability, and constant crying. This is consistent with a direct toxk eflect o SNRs or a dnig iscontunuabon during the third trimester, carefully consider the potential risks and benefits of treatment and consider tapering Effexor XR in the third trimester. Labor, Delivery, Nursing-The effect on labor and delivery in humans is unknown. Venlafaxine and ODV have been reported to be excreted in human milk. Because of the potential for serious adverse
reactions in nursing infants from Effexor XR, a decision should be made whether to discontinue nursing or to reactions in nursing infants from Effexor $X R$, a decision should be made whether to discontinue nursing or to
discontinue the drug, taking into account the importance of the drug to the mother. Pedlatric Use- Safety and Worsening and Suicide Risk). No studies have adequately assessed the impact of Effexor $X R$ on growth, Worsening and Suicide Risk). No studies have adequately assessed the impact of Effexor XR on growth,
development, and maturation of children and adolescents. Studies suggest Effexor XR may adversely affect weight development, and maturation of children and adolescents. Studies suggest Effexor XR may adversely affect weight
and height (see PRECAunONS-General, Changes in Height and Changes in Weight). Should the decision be made to and height (see PRECAUnONs-Ceneral, Changes in Height and Changes in Weight). Should the decision be made to months. in studies in patients aged 6-17, blood pressure and cholesterol increases considered to be clinically relevant 
vasodilatation, thinking abnormal, decreased libido, and sweating. Commonly Observed Adverse Events in Controlled Clinical Tria accidental injury, abdominal pain. Cardiovascular: vasodilatation, hypertension, palpitation. Digestive: nausea System: dizziness, somnolence, insomnia, dry mouth, nervousness, abnormal dreams, tremor, depression, hypertonia, paresthesia, libido decreased, agitation, anxiety, twitching. Respiratory System: pharyngitis, yawn, sinusitis. Skin: sweating. Special Senses: abnormal vision. Urogenital System: abnormal ejaculation, impotence, orgasmic dysfunction (including anorgasmia) in females. Vital Sign Changes: Effexor XR wa associated with a mean increase in pulse rate of about 2 beats/min in depression and GAD thials and a mean increase in pulse rate of 4 beats/min in SAD trials. (See WARMINGS-Sustained Hypertension). Laboratory Changes: Clinically relevant increases in serum cholesterol were noted in Effexor XR clinical trials. Increase were duration dependent over the study period and tended to be greater with higher doses. Other Events Observed During the Premarketing Evaluation of Effexor and Efrexor $x h-N=6,670$. "Frequent $=$ events

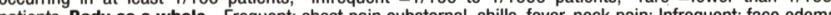
patients. Body as a whole - Frequent. chest pain substernal, chils, fever, neck pain, Infrequent. ace edema, withdrawal syndrome, Rare. appendicits, bacteremia, carcinoma, cellultis. Cardiovascular system- Frequent: hypotension, peripheral vascular, disorder (mainly cold feet and/or cold hands), syncope, thrombophlebitis; Rare: aortic aneurysm, arteritis, first-degree atrioventricular block, bigeminy, bundle branch block, capillary fragility, cerebral ischemia, coronary antery disease, congestive heart falure, heart arest, hematoma Cardiovascular disorder (mitral valve and circulatory disturbance), mucocutaneous hemomage, myocardia dysphagia, tongue edema, esophagitis, gastritis, gastroenteritis, gastrointestinal ulcer, gingivitis, glossitis rectal hemonhe, hemornoids, melena, oral monilasis, stomatitis, mouth ulceration, Rare. abdomina distension, biliary pain, cheilitis, cholecystitis, cholelithiasis, esophageal spasms, duodenitis, hematemesis, gastroesophageal reflux disease, gastrointestnal hemorhage, gum hemorhage, hepatitis, ileitis, jaundice intestinal obstruction, liver tendemess, parotitis, periodontitis, proctitis, rectal disorder, salivary glan enlargement, increased salivation, soft stools, tongue discoloration. Endocrine system - Rare: galactorrhoea goiter, hyperthyroidism, hypothyroidism, thyroid nodule, thyroiditis. Hemic and lymphatic system - Frequen: ecchymosis; Infrequent: anemia, leukocytosis, leukopenia, lymphadenopathy, thrombocythemia; Rare basophilia, bleeding time increased, cyanosis, eosinophilia, lymphocytosis, multiple myeloma, purpura, thrombocytopenia. Metabolic and nutritional - Frequent. edema, weight gain; Infrequent: alkalin phosphatase increased, dehydration, hypercholesteremia, hyperglycemia, hyperlipemia, hypoglycemia, , creatinine increased, diabetes mellitus, glycosuria, gout, healing abnormal, hemochromatosis, hypercalcinuria, hyperkalemia, hyperphosphatemia, hyperuricemia, hypocholesteremia, hyponatremia, hypophosphatemia, hypoproteinemia, uremia. Musculoskeletal system - Frequent: arthralgia; infrequent: arthritis, arthrosis, bon spurs, bursitis, leg cramps, myasthenia, tenosynovitis; Rare: bone pain, pathological fracture, muscle cramp, muscle spasms, musculoskeletal stifness, myopathy, osteopoross, osteosclerosis, plantar fascitis, CNS stimulation, emotional lability, euphoria, hallucinations, hostility, hyperesthesia, hyperkinesia, hypotonia stupor, suicidal ideati aphasia, bradykinesia, buccoglossal syndrome, cerebrovascular accident, feeling drunk, loss of consciousness, delusions, dementia, dystonia, energy increased, facial paralysis, abnormal gait, Guillain-Barre syndrome, homicidal ideation, hyperchlorhydria, hypokinesia, hysteria, impulse control difficulties, libido increased, motion sickness, neuritis, nystagmus, paranoid reaction, paresis, psychotic depression, reflexes decreased, reflexes increased, torticolilis. Respiratory system - Frequent: cough increased, dyspnea; Infrequent: asthma, chest congestion, epistaxis, hyperventiation, laryngismus, laryngitis, pneumonia, voice alteration; Rare: atelectasis, hemoptysis, hypoventiation, hypoxia, larynx edema, pleurisy, pulmonary embolus, sleep apnea. Skin and appendages - Frequent: pruritus; Infrequent: acne, alopecia, contact dermatitis, dry skin, eczema, maculopapular rash, psoriasis, urticaria; Rare: brittle nails, erythema nodosum, exfoliative dermatitis, lichenoid dermatisis, hair discoloration, skin discoloration, furunculosis, hirsutism, leukoderma, miliaria, petechial rash, pruritic rash, pustular rash, vesiculobullous rash, seborrhea, skin atrophy, skin hypertrophy, skin striae, swealing decreased. Special senses - Frequent, abnomally of acc mydriasis, taste perversion; Infrequent: conjunctivitis, diplopia, dry eyes, eye pain, hyperacusis, otitis media parosmia, photophobia, taste loss, visual field defect; Rare: blepharitis, cataract, chromatopsia, conjunctiva edema, corneal lesion, deafness, exophthalmos, eye hemorrhage, glaucoma, retinal hemorrhage, subconjunctival hemorrhage, keratitis, labyrinthitis, miosis, papiliedema, decreased pupillary reflex, otiti externa, scleritis, uveitis. Urogenital system - Frequent: prostatic disorder (prostatitis, enlarged prostate, and prostate irritability), urination impaired; Infrequent: albuminuria, amenorrmea, breast pain, cystitis, dysuria, hematuria, kidney calculus, kidney pain, leukormea, menormhagia, metrom agia, nocturia, polyuria, pyuria, urinary incontinence, urinary retention, urinary urgency, vaginal hemorrhage, vaginitis; Rare. abortion, anuria, balanitis, bladder pain, breast discharge, breast engorgement, breast enlargement, endometriosis, female lactation, fibrocystic breast, calcium crystalluria, cervicitis, orchitis, ovarian cyst, prolonged erection, salpingitis, urolithiasis, uterine hemorhage, uterine spasm, vaginal dryness. Postmarketing Reports: thrombophlebitis, delirium EKG abnormalities such as QT prolongation; cardiac arrhythmias including atria fibrillation, supraventricular tachycardia, ventricular extrasystoles, and rare reports of ventricular fibrilation and ventricular tachycardia, including torsades de pointes; epidermal necrosis/Stevens-Johnson syndrome, erythema multiforme, extrapyramidal symptoms (including dyskinesia and tardive dyskinesia), angle-closure glaucoma, hemorrhage (including eye and gastrointestinal bleeding), hepatic events (including GGT elevation; (10-year-old been taking methylphenidate, was treated and recovered, neutropenia, night sweats, pancreatitis, pancytopenia panic, prolactin increased, pulmonary eosinophilia, renal failure, rhabdomyolysis, serotonin syndrome shock-like electrical sensations or tinnitus (in some cases, subsequent to the discontinuation of venlafaxine or tapering of dose), and SIADH (usually in the elderly). Elevated clozapine levels that were temporally associated with adverse events, including seizures, have been reported following the addition of venlafaxine. Increases in prothrombin time, partial thromboplastin time, or INR have been reported when venlafaxine was given to patients on warfarin therapy. DRUG ABUSE AND DEPENDENCE: Effexor XR is not a controlled substance. Evaluate patients carefully for history of drug abuse and observe such patients closely for signs of misuse or abuse. OVERDOSAGE: Electrocardiogram changes (e.g., prolongation of QT interval, bundle branch block, QRS prolongation), sinus and ventricular tachycardia, bradycardia, hypotension, altered level of consciousness (ranging from somnolence to coma), rhabdomyolysis, seizures, vertigo, liver necrosis, and death have been reported. Treatment should consist of those general measures employed in the management of overdosage with any antidepressant. Ensure an adequate airway, oxygenation and ventilation. Monitor cardiac rhythm and vital signs. General supportive and symptomatic measures are also recommended. Induction of emesis is not recommended. Gastric lavage with a large bore orogastric tube with appropriate airway protection, if needed, may be indicated if performed soon after ingestion or in symptomatic patients. Activated charcoal should be administered. Due to the large volume of distribution of this drug, forced diuresis, dialysis, hemoperfusion, and exchange transfusion are unlikely to be of benefit. No specific antidotes for venlafaxine are known. In managing overdosage, consider the possibility of multiple drug involvement. Consider contacting a poison control center for additional information on the treatment of overdose. Telephone numbers for certified poison control centers are listed in the Physicians' Desk Reference ${ }^{\circ}$ (PDR). DOSAGE AND ADMINISTRATION: Consult full prescribing information for dosing instructions. Switching Patients to or From an MAOI-At least 14 days should elapse between discontinuation of an MAOl and initiation of therapy with Effexor XR. At least 7 days should be allowed after stopping Effexor XR before starting an MAOl (see W10404C019, revised November 2005 constipation, anorexia vomiting flatulence, diarrhea eructation. Metabolic/Nutritional: weight loss. Nervous intentional injury, malaise, moniliasis, neck rigidity, pelvic pain, photosensitivity reaction, suicide attempt migraine, postural hypotension, tachycardia, Infrequent: angina pectoris, armhythmia, extrasystoles, infarct, pallor, sinus arrhythmia. Digestive system - Frequent. increased appetite, Infrequent: bruxism, colitis, gynecomastia (male), hypomenorrhea, kidney function abnormal, mastitis, menopause, pyelonephritis, oliguria,

\section{Take a closer look at}

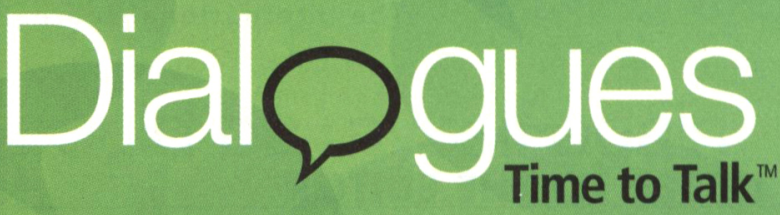

is a unique patient support and

education program that is designed to

help you foster successful therapy

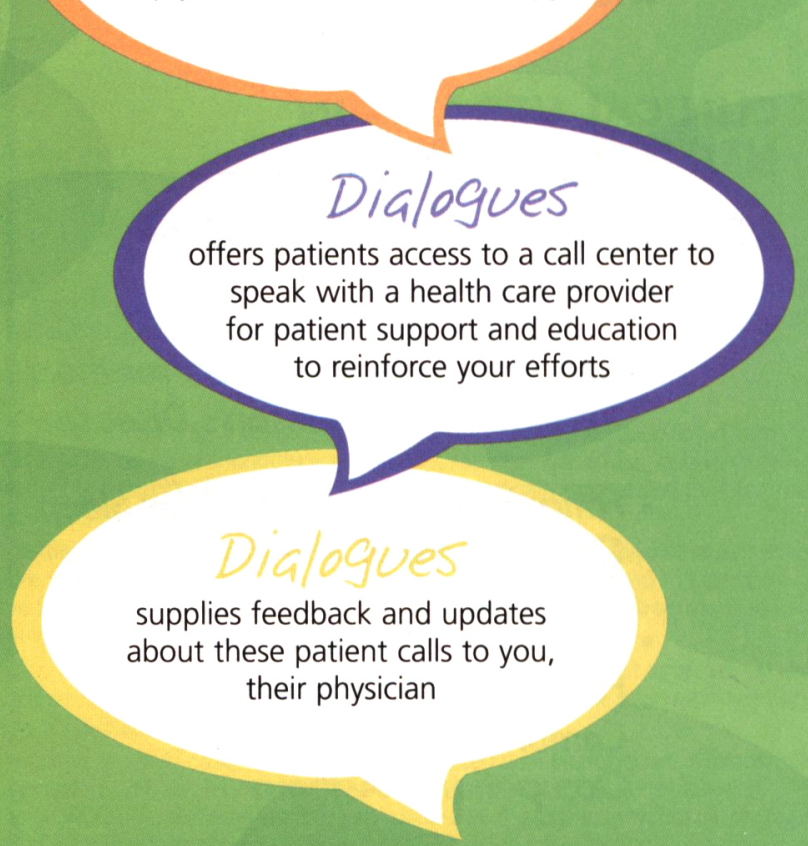

Encourage your EFFEXOR XR patients to enroll in Dialogues by calling 866-313-3737 - and you can visit mddpatientsupport.com

The most common adverse events reported in EFFEXOR XR short-term placebo-controlled depression, generalized anxiety disorder (GAD), social anxiety disorder (SAD), and/or panic disorder (PD) trials (incidence $\geq 10 \%$ and $\geq 2 x$ that of placebo) were anorexia, asthenia, constipation, dizziness, dry mouth, ejaculation problems, impotence, insomnia, nausea, nervousness, somnolence, and sweating.

ONCE-DAILY

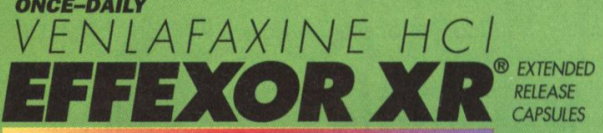

\section{The change they deserve.}

References: 1. Data on file, Wyeth Pharmaceuticals Inc. 2. Effexor XR (venlafaxine Wyeth Pharmaceuticals Inc.
Please see brief summary of Prescribing Information on adjacent pages. s

(n) 
The International Journal of Neuropsychiatric Medicine

\section{CLINICAL UPDATES IN NEUROPSYCHIATRY}

\section{News From the Field of Neuroscience}

- FDA Approves Rivastigmine Tartrate for the Treatment of Parkinsons' Disease Dementia

- Identification of Common Genetic Traits Across Different Disorders May Improve Treatment

- Paroxetine May Benefit Patients with Dysthmic Disorder

- History of Past Traumatic Incidents not Increased Among OCD

Patients

- Schizophrenia May be More Severe in Patients with Tardive Dyskinesia

\section{PEARLS IN CLINICAL NEUROSCIENCE}

\section{The Cognitive-Affective Neuroscience of the Unconscious}

Dan J. Stein, MD, PhD, University of Cape Town; Mark Solms, PhD, University of Cape Town; and Jack van Honk, PhD, Utrecht University

\section{CME QUIZ}

\section{The quiz is CME-accredited by Mount Sinai School of Medicine for $\mathbf{3 . 0}$ credit hours.}

Founded in 1996, CNS Spectrums is indexed in Index Medicus and is available on MEDLINE under the citation CNS Spectr. CNS Spectrums is also distributed to all CINP members and is accredited for international CME by EACIC.

CNS Spectrums (ISSN 1092-8529) is published monthly by MBL Communications, Inc. 333 Hudson Street, 7th Floor, New York, NY 10013.

One-year subscription rates: domestic $\$ 120$; foreign $\$ 195$; in-training $\$ 85$. For subscriptions: Tel: 212-328-0800; Fax: 212-328-0600; Web: www.cnsspectrums.com. Single issues: \$15 - E-mail ks@mblcommunications.com

For editorial inquiries, please fax us at 212-328-0600 or E-mail José $\mathrm{R}$. Ralat at jr@mblcommunications.com. For bulk reprint purchases, please contact Christopher Naccari at cdn@mblcommunications.com.

Subscribers: send address changes to CNS Spectrums c/o MMS, Inc., 185 Hansen Court, Suite 110, Wood Dale, IL 60191-1150.
Opinions and views expressed by authors are their own and do not necessarily reflect the views of the publisher, MBL Communications, Inc., CNS Spectrums, LLC, or the editorial advisory board.

Advertisements in CNS Spectrums are accepted on the basis of adherence to ethical medical standards, but acceptance does not imply endorsement by CNS Spectrums or the publisher.

CNS Spectrums is a registered trademark of CNS Spectrums, LLC, New York, NY. Permission to reproduce articles in whole or part must be obtained in writing from the publisher

BPA BPA member since July 2005.

Copyright ${ }^{\circ} 2006$ by MBL Communications, Inc. All rights reserved Printed in the United States.

This month's issue of CNS Spectrums, as well as a host of educational resources, enduring materials, and archived issues, is available at www.cnsspectrums.com. 


\section{I never thought I could be myself again}
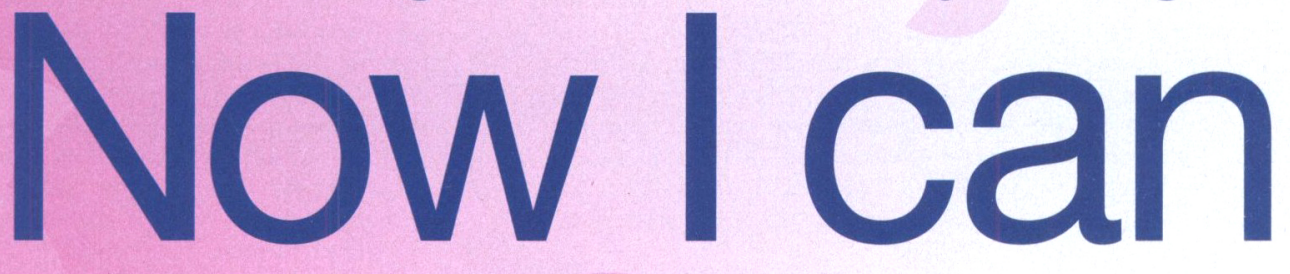

\#1

Now the most prescribed atypical*

\section{Proven efficacy}

To help patients achieve continued success ${ }^{\dagger 1-4}$

\section{Trusted tolerability}

\section{To help patients stay on treatment ${ }^{1-5}$}

SEROQUEL is indicated for the treatment of acute manic episodes associated with bipolar I disorder, as either monotherapy or adjunct therapy with lithium or divalproex, and the treatment of schizophrenia. Patients should be periodically reassessed to determine the need for continued treatment.

Elderly patients with dementia-related psychosis treated with atypical antipsychotic drugs are at an increased risk (1.6 to 1.7 times) of death compared to placebo ( $4.5 \%$ vs $2.6 \%$, respectively). SEROQUEL is not approved for the treatment of patients with dementia-related psychosis.

Prescribing should be consistent with the need to minimize the risk of tardive dyskinesia. A rare condition referred to as neuroleptic malignant syndrome has been reported with this class of medications, including SEROQUEL.

Hyperglycemia, in some cases extreme and associated with ketoacidosis, hyperosmolar coma, or death, has been reported in patients treated with atypical antipsychotics, including SEROQUEL. Patients starting treatment with atypical antipsychotics who have or are at risk for diabetes should undergo fasting blood glucose testing at the beginning of and during treatment. Patients who develop symptoms of hyperglycemia should also undergo fasting blood glucose testing.

Precautions include the risk of seizures, orthostatic hypotension, and cataract development.

The most commonly observed adverse events associated with the use of SEROQUEL in clinical trials were somnolence, dry mouth, dizziness, constipation, asthenia, abdominal pain, postural hypotension, pharyngitis, SGPT increase, dyspepsia, and weight gain.

*All atypical prescriptions: Total prescriptions. Jan. 05-Feb. 06. New prescriptions. Sept. 04-Feb. 06. IMS Health. National Prescription Audit.

t Significant improvement in all 11 YMRS items was measured at Day 21 and continued through Day 84 in monotherapy mania trials.

Please see Brief Summary of Prescribing Information on adjacent page.

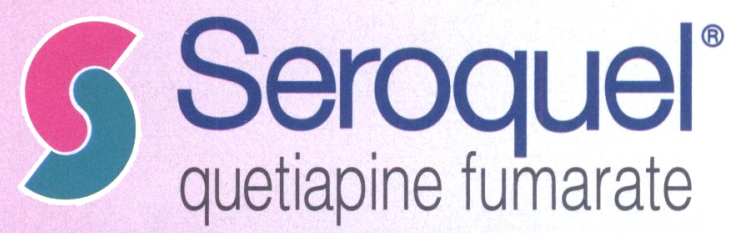

$25 \mathrm{mg}, 50 \mathrm{mg}, 100 \mathrm{mg}, 200 \mathrm{mg}, 300 \mathrm{mg} \& 400 \mathrm{mg}$ tablets

\section{Redefine Success}


